\title{
EFFECTS OF GEOGRID REINFORCEMENT IN LOW VOLUME FLEXIBLE PAVEMENT
}

\author{
Minkwan KIM ${ }^{\mathrm{a}}$, Joo Hyoung LEE ${ }^{\mathrm{b}}$ \\ ${ }^{a}$ Shell International Exploration and Production, 200 North Dairy Ashford, Houston, TX 77079, USA \\ ${ }^{b}$ Department of Construction Science and Organizational Leadership, Purdue University Calumet, \\ 2200 169th St., Hammond, IN 46323, USA
}

Received 22 Apr 2011; accepted 23 Nov 2011

\begin{abstract}
This paper presents findings of a study on geogrid reinforced flexible pavement in a low volume road through a three-dimensional finite element analysis. A mechanistic model was developed for geogrid reinforced flexible pavement. To analyze the behavior of pavement foundation, stress-dependent resilient modulus models were employed in both base and subgrade layers. The model also incorporated previous research findings to enhance the reliability of the analysis. During the analysis, comparisons were made to contrast the responses of low volume flexible pavement with and without geogrid. The results show geogrid reinforcement reduces critical pavement responses under traffic loading, such as vertical surface deflection, tensile strain in asphalt concrete, and compressive strain in subgrade. The study found up to $18 \%$ reduction of vertical strain at the top of subgrade and $68 \%$ reduction of tensile strain at the bottom of asphalt concrete. Also, geogrid provides confining stresses in the adjacent aggregate layer, which leads to surrounding layers becoming stiffer. Based on the results of this study, the placement of geogrid reinforcement on top of weak subgrade was found particularly effective compared to that on strong subgrade.
\end{abstract}

Keywords: geogrid, flexible pavement, three-dimensional finite element analysis, nonlinear analysis, resilient modulus.

Reference to this paper should be made as follows: Kim, M.; Lee, J. H. 2013. Effects of geogrid reinforcement in low volume flexible pavement, Journal of Civil Engineering and Management 19(Supplement 1): S14-S22.

http://dx.doi.org/10.3846/13923730.2013.793606

\section{Introduction}

Geogrid is known as a reinforcement material that has been used to increase stability and improve performance of soft and weak subgrade in roadways. Being placed between pavement layers, it provides subgrade restraint, stabilizes aggregate particles, and increases the bearing capacity of a pavement structure. The lateral restraint coupled with membrane tension effects improves the load carrying capacity of the geogrid reinforced pavement structure. This improvement helps to reduce the thickness of the base layer as the subgrade restraint increases the bearing capacity of pavement. Hence, the installation of geogrid is found especially effective in low volume roads with thinly surfaced flexible pavement. Being used in flexible pavement, geogrid provides tensile reinforcement for base aggregates and leads to friction between geogrid and the aggregate layer. These can increase stability in pavement and improve the performance of pavement materials, primarily by interlocking geogrid with the base aggregate layer and separating the base material from subgrade.

The current method being used in geogrid reinforced pavement design is based on an empirical method using
Traffic Benefit Ratio (TBR). In parallel with recent AASHTO's move toward employing the mechanistic concept in design, the finite element (FE) method became an effective analysis method (National Cooperative Highway Research Program 2004). Pavement responses, such as stress, strain, and deflection, can be computed as a result of mechanistic analysis. These will then be the key components to predict rutting and fatigue life of pavement using a transfer function. However, computing accurate pavement responses is still challenging due mainly to the complicated behavior of pavement geomaterials under wheel loading and interaction between the pavement layers. To improve the accuracy in the analysis of geogrid reinforced pavement responses, it is significant to properly model the pavement material characteristics and the interaction between geogrid and flexible pavement layers.

This paper describes an FE model used for an analysis of pavement responses in geogrid reinforced flexible pavement. The primary objective of the study is to investigate the improved structural capacity of pavement and its performance as a result of geogrid reinforcement. A three-dimensional (3D) nonlinear FE model was developed for the analysis taking into consideration the effects of

Corresponding author: Joo Hyoung Lee

E-mail: leej@purduecal.edu 
different material properties and characteristics of geogrid. Particularly, three directional geogrid properties, that is, those in machine, cross-machine, and normal directions, were employed to incorporate the directional dependence of elastic properties. Since geomaterials in the pavement foundation exhibit a stress-dependent resilient behavior, resilient geomaterial models were used to predict accurate pavement responses. Besides the geogrid properties, pavement material characteristics and different pavement thicknesses were considered during the analysis. Discussions in this paper include comparisons of low volume flexible pavement with geogrid reinforced pavement based on the results of the 3D nonlinear FE analysis.

\section{Mechanisms of geogrid reinforcement in pavements}

In order to compute accurate pavement responses in geogrid reinforced pavement, the reinforcing mechanisms of geogrid were incorporated into modelling. According to the literature, there are three mechanisms of geogrid reinforcement that must be considered in a pavement analysis: lateral restraint, tensioned membrane, and modified shear failure (Perkins, Ismeik 1997). First, the lateral restraint is induced by friction and interlocking between the aggregate layer and geogrid. The lateral restraint effect is the function of the sizes of geogrid aperture and base aggregates, which improves the lateral and shear strains in the base courses. Second, geogrid behaves like a membrane which resists to tensile forces. The tensile stress developed in a deformed geogrid membrane improves the vertical stress distribution by a so-called tensioned membrane effect. This effect reduces the vertical pavement response at the top of subgrade. Perkins and Ismeik (1997) showed this effect is significant in weak subgrade with a California Bearing Ratio (CBR) of less than 3\%. Third, geogrid can increase the bearing capacity of subgrade by providing a higher total resistance and reinforce the base aggregate layer, if they are interfaced with a failure surface.

Several studies have been conducted to address the applicability of geogrid in flexible pavement with unbound aggregate base and subgrade layers. They also evaluate the potential improvement of structural capacity and performance. Haas (1984), Haas et al. (1988) show the effect of geogrid reinforcement in flexible pavement. The structural performance, such as fatigue and rutting, and benefits from geogrid reinforcement are discussed. The lab experiments of Haas et al. (1988) show 30\% reduction of the maximum tensile strain in asphalt concrete and $20-40 \%$ decrease in the maximum vertical strain in subgrade. Also, the thickness of the base layer is reduced by $25-50 \%$.

Perkins (2001) discusses several considerations in FE modelling for geogrid reinforced flexible pavement. His model was created to replicate the conditions in pavement test sections. Membrane elements were used for geogrid and a contact interface was used between geogrid and the base aggregate layer. Models of unreinforced and reinforced pavement sections were created and compared with test section results. A bounding surface plasticity model was used for the base aggregate and subgrade layers. A Coulomb prediction model was used to describe shear interaction. This model was calibrated from a series of pull out test. The results of the study show the reduction of lateral strain at the bottom of the base, an increase in mean stress confinement in the aggregate layer adjacent to geogrid, an improved vertical stress distribution at the top of subgrade, and a reduction of shear stress at the top of subgrade. According to Perkins (2001), in order to see significant effects from geogrid reinforcement, the elastic modulus of the material needed to be increased by approximately an order to magnitude. This is presumably because of the elastic modulus determined by common tension tests without additional considerations.

Leng and Gabr (2002) conducted a numerical analysis using ABAQUS to investigate the performance of geogrid reinforced aggregates over soft subgrade soil. The results of the numerical study revealed that the installation of geogrid between base layer and subgrade layer reduce the surface deflection on the unpaved structure and improve the stress distribution inside base and subgrade layers. Results also show a significant vertical strain at the bottom of the base layer. Geogrid provided tensile resistance to limit the lateral spread of aggregates in the base layer and decreased the vertical strain generated at the bottom of the base layer. This improvement led to decreased thickness of the base layer. The geogrid layer with higher tensile modulus provided better attenuation of stresses than that with lower tensile modulus did.

Saad et al. (2006) show the results of a series of FE analyses and the benefits of high modulus geosynthetic reinforcement in the pavement foundation. This study employed a 3D modelling technique in the regime of dynamic loadings. The model used elastoplastic DruckerPrager materials for base and Modified Cam Clay model for subgrade. A parametric study was performed to study the performance of the geosynthetic reinforcement pavement system relative to the base thickness, base quality, subgrade quality, and the location of geosynthetic. The study found that placing geosynthetic reinforcement at the base-asphalt concrete interface leads to the highest reduction of fatigue strain. The placement of geosynthetic reinforcement in a thin base layer was found particularly effective. The highest decrease of rutting strain occurred when reinforcement was placed at $1 / 3$ of thickness from the bottom of base. The study shows that the range of reduction on subgrade rutting strains varies between 11 and $34 \%$ according to the various locations of reinforcement, the thickness of the base layer, and the quality of subgrade materials. The highest amount, $48 \%$, of decrease in fatigue strain was observed when reinforcement was placed at the interface between asphalt concrete and the base layer.

Kwon et al. (2008) conducted a mechanistic analysis using an axisymmetric FE model and solved for the pavement responses under traffic loading. The model employed the resilient modulus and approximated a wheel load by using a circular uniform load in axisymmetric flexible pavement. According to the study, geogrid reinforcement can develop stiffer layer associated with interlocking actions between geogrid and the aggregates 
layer. The installation of geogrid resulted in up to $62 \mathrm{kPa}$ of residual stress in the aggregate base layer. The predicted pavement responses through several analyses show up to $3.2 \%$ reduction of tensile strain at the bottom of the asphalt concrete layer and $26.5 \%$ reduction of vertical strain at the top of the subgrade layer.

\section{Considerations of geogrid and pavement modelling}

Several considerations were made in modelling geogrid reinforced flexible pavement in this study. First, the study employed a 3D nonlinear FE model for more accurate presentation of pavement behavior. Several studies (Schwartz 2002; Saad et al. 2005; Kim et al. 2009; Kim, Lee 2011) show that pavement responses are on account of the nonlinear behavior of base and subgrade layers, which can be better analyzed through a nonlinear modelling. It is known that nonlinear material properties considering residual stress from aggregate-geogrid interaction are important factors especially in thinly surfaced low volume flexible pavement. Nonetheless, the nonlinearity of soil behavior has been paid less attention in previous studies. In addition, this study applied an FE model to present 3D behavior of geogrid reinforced pavement, which is believed to better predict actual pavement responses according to the previous studies (Schwartz 2002; Saad et al. 2005; Kim et al. 2009; Kim, Lee 2011).

Second, geogrid reinforcement was placed between the aggregate base layer and subgrade. The purpose of placing geogrid between the base layer of pavement and subgrade is to analyze the effect of base reinforcement and subgrade restraints. It is also effective in presenting the influence of geogrid reinforcement, such as friction resistance, on the flexible pavement responses as a result of nonlinear behavior of base and subgrade materials. This study used the contact model in ABAQUS (HKS 2005) to analyze these interactions between geogrid and the pavement layers. To present the friction resistance between geogrid and surrounding materials, a contact algorithm was specified at the bottom of base, geogrid, and at the top of subgrade. The contact algorithm can be formulated considering surface-based contact between contacting bodies associated with undergoing small sliding. When two surfaces are in contact they tend to transmit shear and normal forces across their interface. The relationship between these two force components is known as friction, generally represented by a friction coefficient. This relationship is well explained by Coulomb friction model. The Coulomb friction model, represented by Eqn (1), defines this critical shear stress, $\tau_{\text {crit }}$, at which the sliding of the surfaces starts as a fraction of the contact pressure, $p$, between the surfaces:

$$
\tau_{\text {crit }}=\mu p,
$$

where $\mu$ is the coefficient of friction.

Third, the study used 4-node membrane elements in modelling geogrid reinforcement. Placed between the base layer and subgrade, the membrane elements were formulated to possess in-plane/out-of-plane tensile and shear strength. The membrane elements, however, do not exhibit bending behavior. The contact algorithm in ABAQUS (HKS 2005) incorporates various bonding conditions to represent the friction resistance at the soil/ aggregate-geogrid interface as a primary reinforcement mechanism. The coefficient of friction is assumed 1.0 in this study (Kwon et al. 2005).

Fourth, geogrid reinforcement is expected to provide the effect of confinement to the aggregates at the vicinity of geogrid and thereby increasing layer stiffness. The interlocking behavior between aggregates and geogrid has been verified via experimental and analytical approaches in many studies. The FE response model (Perkins, Edens 2002) revealed that geogrid reinforcement prevents lateral spreading of the bottom of the base aggregate layer in contact with geogrid. Confinement of the aggregate layer leads to increased stiffness in aggregates and reduced vertical compressive strain and surface deflection in geogrid reinforced pavement. Also, Konietzky et al. (2004) and McDowell et al. (2006) investigated aggregates and geogrid interactions and modelled confinement effects using 3D Particle Flow Code (PFC) Discrete Element Method (DEM) program. Utilizing discrete elements, the studies discovered the area of interaction between geogrid and surrounding aggregates. The results of confinement led to the development of considerable horizontal residual stress at the vicinity of geogrid when applied loading is removed. The developed residual stress could be directly resulted from the increased confinement and stiffness attributed to geogrid reinforcement in flexible pavement. They also found that this effect occurs in consequence of stiffened zone with large layer modulus, observed within approximately $10 \mathrm{~cm}$ from the place where geogrid is installed. Such confinement was considered in this study to take in account the interlocking effect on the aggregates adjacent to geogrid.

\section{Nonlinearity of materials in pavement}

The behavior of pavement layers due to traffic loading may include resilient deformation and permanent deformation. If the stress due to applied wheel loading is much smaller than the strength of pavement material or the stress is repeated by a large number of applications, the permanent deformation per each wheel loading becomes negligible. Hence, the load-deformation behavior can be considered elastic or resilient in the mechanistic analysis of flexible pavement structures. This behavior has been commonly represented in terms of resilient modulus as follows:

$$
M_{R}=\frac{\sigma_{d}}{\varepsilon_{r}},
$$

where: $M_{R}$ is resilient modulus; $\sigma_{d}$ is deviator stress; and $\varepsilon_{r}$ is recoverable strain.

Two stress-dependent resilient modulus models are often used to characterize pavement materials. Witczak and Uzan's (1988) Universal model is used for base material; and Thompson and Robnett's (1979) Bilinear model is applied to subgrade. In this study, these models were used to compute pavement responses under wheel loads in order to investigate the behaviors of pavement 
and geomaterials. The following details the considerations incorporated into the nonlinear 3D FE analyses.

The Universal model (Witczak, Uzan 1988) for base layers considers the effects of confining and octahedral shear stress in order to model the stress dependent modulus distribution. This model considers material characteristics in all three directions, so that it is suited to $3 \mathrm{D}$ FE pavement analyses. The Universal model (Witczak, Uzan 1988) is expressed in Eqn (3):

$$
M_{R}=K_{1} p_{a}\left(\frac{I_{1}}{p_{a}}\right)^{K_{2}}\left(\frac{\tau_{o c t}}{p_{a}}\right)^{K_{3}},
$$

where: $M_{R}$ is resilient modulus; $I_{1}=\sigma_{1}+\sigma_{2}+\sigma_{3} ; \tau_{o c t}=$ $1 / 3 \sqrt{\left(\sigma_{1}-\sigma_{2}\right)^{2}+\left(\sigma_{1}-\sigma_{3}\right)^{2}+\left(\sigma_{2}-\sigma_{3}\right)^{2}} ; p_{a}$ is atmospheric pressure; and $K_{1}, K_{2}$, and $K_{3}$ are material coefficients from multiple regression analyses of the repeated load triaxial test data. The resilient modulus represents the ratio of repeated deviator stress to recoverable lateral strain, based on the results of constantconfining-pressure triaxial tests.

The Bilinear model (Thompson, Robnett 1979) is one of the most commonly used resilient modulus models for subgrade soils. The resilient modulus of fine-grained subgrade soil is dependent upon the current stress state. The Bilinear model is expressed in Eqn (4):

$$
\begin{aligned}
& M_{R}=K_{1}+K_{3}\left(K_{2}-\sigma_{d}\right) \text { when } \sigma_{d} \leq K_{2} ; \\
& M_{R}=K_{1}-K_{4}\left(\sigma_{d}-K_{2}\right) \text { when } \sigma_{d} \geq K_{2},
\end{aligned}
$$

where: $M_{R}$ is resilient modulus; $\sigma_{d}$ is deviator stress; $K_{1}$, $K_{2}, K_{3}$, and $K_{4}$ are model parameters obtained from repeated load triaxial tests.

This study used a 3D nonlinear model to analyze the response of geogrid reinforced flexible pavement. Originally developed by Kim et al. (2009), the model incorporated the Universal (Witczak, Uzan 1988) and Bilinear models (Thompson, Robnett 1979) using a user material (UMAT) subroutine in ABAQUS (HKS 2005). Kim et al. (2009) used the model in computing nonlinear resilient modulus distributions within the base layer and subgrade subject to single wheel loading. The model was validated through comparison of nonlinear FE analysis results with the field-measured pavement responses of a traffic test conducted by the National Airport Pavement Test Facility (NAPTF) using multiple wheel loading. Overall, the FE analysis results were consistent with the measured responses of the test section. Particularly, the analysis results of subgrade vertical stress and surface deflection were in agreement with the measured values in the testing section.

\section{Pavement analysis results}

The mechanistic model developed in this study has the following features. The flexible pavement layers are modelled as 3D solid elements. All pavement layers are modelled incorporating nonlinear material properties to better represent proper characterization of stress-dependent resilient modulus.

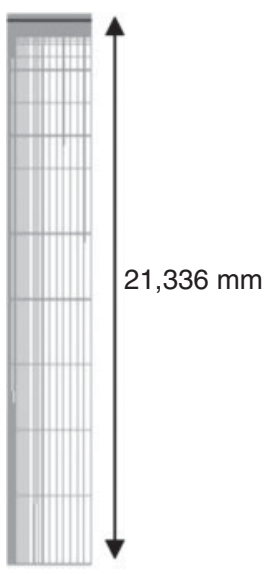

(a) Section view



$3,048 \mathrm{~mm}$

(b) Plan view
Fig. 1. 3D FE meshes used in geogrid reinforced flexible pavement: (a) Section view; (b) Plan view

Figure 1 shows the FE models for pavement and geogrid reinforcement used in this study. The pavement structure extends to infinity in horizontal and vertical directions. The domain size for the pavement model was determined to compute the most accurate pavement responses. A recent study by Kim et al. (2009) proved that the domain size of 140 times the radius of a circular loading, $R(R=152.4 \mathrm{~mm}$ herein), in the vertical direction and 20 times $R$ in the horizontal direction consistently give accurate results when pavement is subject to an equivalent single wheel loading. Hence, the same domain size was used in this study. As shown in Figure 1, the model consists of the 8-node isoparametric hexahedron elements in a 3D mesh with $21,336 \mathrm{~mm}$ in the vertical direction and $3048 \mathrm{~mm}$ in the horizontal direction. All vertical boundary nodes have roller supports with fixed horizontal boundary nodes used at the bottom. A uniform pressure of $550 \mathrm{kPa}$ was applied over a circular area with the radius $R$ of $152.4 \mathrm{~mm}$.

To evaluate the responses of geogrid reinforced flexible pavement, four different flexible pavement geometries were chosen as shown in Table 1. The flexible pavement geometries included thin asphalt concrete layers of $38 \mathrm{~mm}$ and $76 \mathrm{~mm}$ with two different base layer thicknesses ranging from relatively thin to substantially thick base layers for low volume pavement.

Using the developed ABAQUS UMAT subroutine, nonlinear stress-dependent material models were employed to analyze geogrid reinforced flexible pavement with four different geometric configurations. Table 2

Table 1. Pavement scenarios and geometries

\begin{tabular}{lcc}
\hline Pavement scenario & $\begin{array}{c}\text { Thickness of asphalt } \\
\text { concrete }(\mathrm{mm})\end{array}$ & $\begin{array}{c}\text { Thickness of } \\
\text { base }(\mathrm{mm})\end{array}$ \\
\hline Pavement 1 & 38 & 152 \\
Pavement 2 & 38 & 304 \\
Pavement 3 & 76 & 152 \\
Pavement 4 & 76 & 304 \\
\hline
\end{tabular}


Table 2. Pavement material properties used in the FE analyses

\begin{tabular}{|c|c|c|c|c|c|}
\hline Layer & $v$ & \multicolumn{4}{|c|}{ Material properties } \\
\hline \multirow[t]{2}{*}{ Asphalt concrete } & 0.35 & \multicolumn{4}{|c|}{ Isotropic and linear elastic $(\mathrm{E}=2759 \mathrm{MPa})$} \\
\hline & \multirow{3}{*}{0.4} & \multicolumn{4}{|c|}{ Isotropic and nonlinear: Universal model by Witczak and Uzan (1988) - Eqn (3) } \\
\hline \multirow[t]{2}{*}{ Base } & & & $\mathrm{K}_{1}$ & $\mathrm{~K}_{2}$ & $\mathrm{~K}_{3}$ \\
\hline & & & 5988 & 0.63 & -0.18 \\
\hline \multirow{3}{*}{$\begin{array}{l}\text { Subgrade-strong } \\
\text { subgrade }\end{array}$} & \multirow{3}{*}{0.45} & \multicolumn{4}{|c|}{ Isotropic and nonlinear: Bilinear model by Thompson and Robnett (1979) - Eqn (4) } \\
\hline & & $\mathrm{K}_{1}(\mathrm{MPa})$ & $\mathrm{K}_{2}(\mathrm{kPa})$ & $\mathrm{K}_{3}$ & $\mathrm{~K}_{4}$ \\
\hline & & 85.1 & 42.8 & 1110 & 178 \\
\hline \multirow{3}{*}{$\begin{array}{l}\text { Subgrade-weak } \\
\text { subgrade }\end{array}$} & \multirow{3}{*}{0.45} & \multicolumn{4}{|c|}{ Isotropic and nonlinear: Bilinear model by Thompson and Robnett (1979) - Eqn (4) } \\
\hline & & $\mathrm{K}_{1}(\mathrm{MPa})$ & $\mathrm{K}_{2}(\mathrm{kPa})$ & $\mathrm{K}_{3}$ & $\mathrm{~K}_{4}$ \\
\hline & & 20.8 & 42.8 & 1110 & 178 \\
\hline \multirow{3}{*}{ Geogrid } & \multirow{3}{*}{0.35} & \multicolumn{4}{|c|}{ Anisotropic properties (Saad et al. 2006) } \\
\hline & & $\mathrm{E}_{\mathrm{xm}}(\mathrm{MPa})$ & $\mathrm{E}_{\mathrm{m}}(\mathrm{MPa})$ & $\mathrm{E}_{\mathrm{n}}(\mathrm{MPa})$ & $\mathrm{G}(\mathrm{MPa})$ \\
\hline & & 2729 & 2539 & 4231 & 30 \\
\hline
\end{tabular}

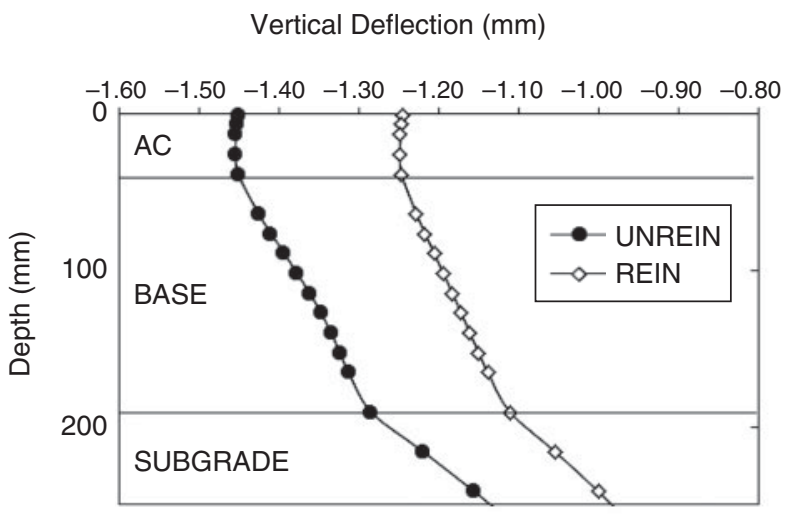

(a) Pavement 1 with weak subgrade

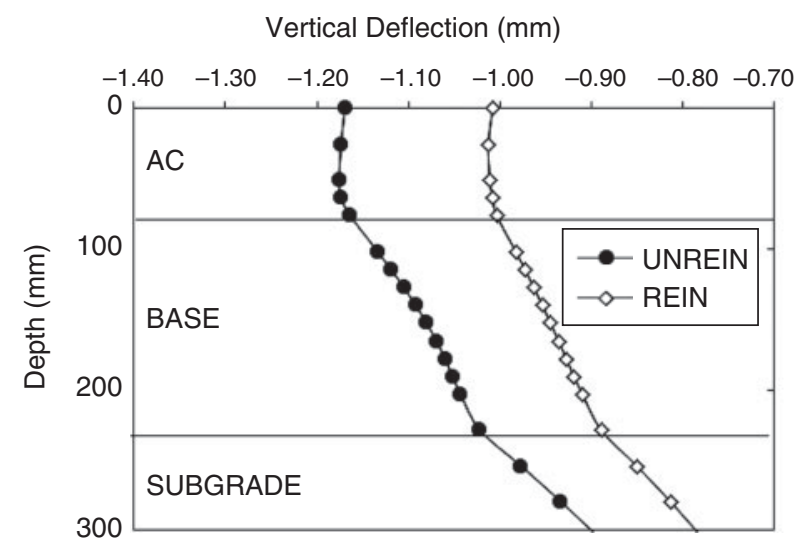

(c) Pavement 3 with weak subgrade

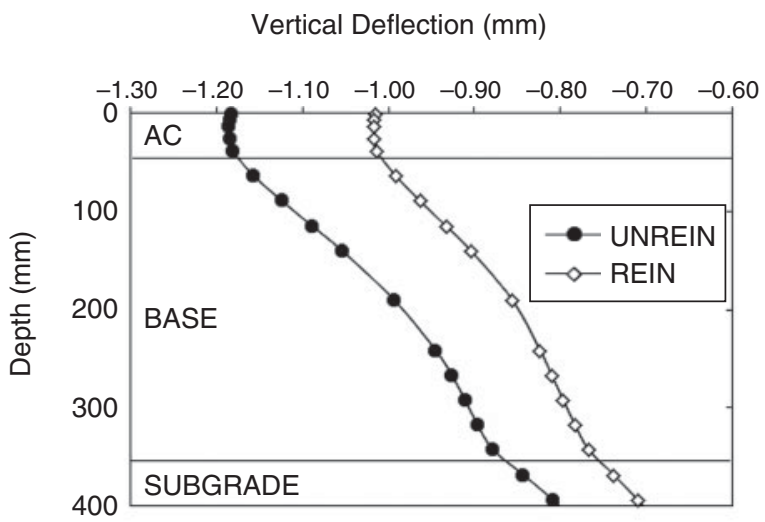

(b) Pavement 2 with weak subgrade

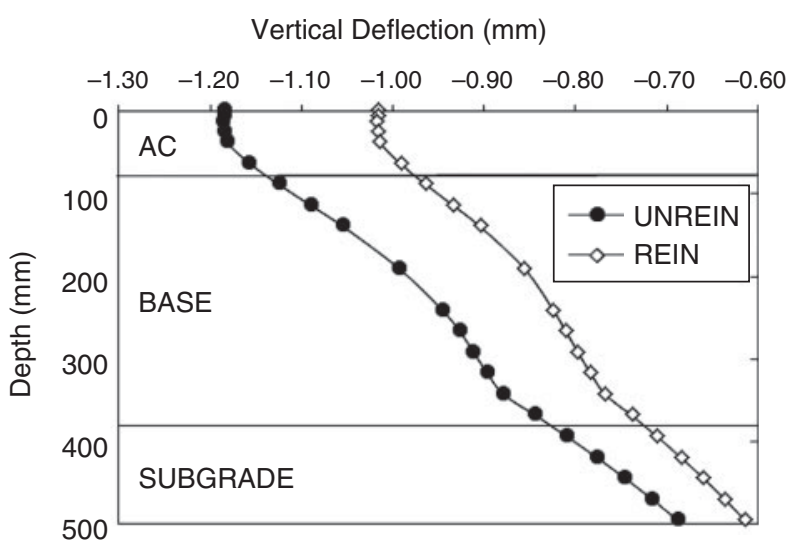

(d) Pavement 4 with weak subgrade

Fig. 2. Predicted vertical deflections at the centreline of loading: (a) Pavement 1 with weak subgrade; (b) Pavement 2 with weak subgrade; (c) Pavement 3 with weak subgrade; (d) Pavement 4 with weak subgrade 
shows pavement material properties used in the FE analysis. The parameters of the Universal model (Witczak, Uzan 1988) and the Bilinear model (Thompson, Robnett 1979) are obtained from repeated load triaxial tests. In order to focus on the nonlinear, stress-dependent behavior of the base and the subgrade materials in the low volume roads, asphalt concrete material was assumed to show linear behavior. The directional dependence of elastic properties was included in modelling geogrid. The subscripts of " $\mathrm{m}$ " and "xm" denote in-plane machine and cross-machine directions, respectively. The direction normal to the plane of geogrid is indicated as " $n$ ". In this study, the thickness of geogrid is considered $1 \mathrm{~mm}$. The 4node membrane elements for geogrid and adjacent 8 -node hexahedron elements for base and subgrade are placed at the soil/aggregate-geogrid interface.

To investigate the effect of geogrid, the results of FE analyses in unreinforced pavement were used as a control value. Geogrid reinforced pavement was then compared to the unreinforced one. The analysis focused on investigating how geogrid reinforcement would impact the predicted pavement responses in terms of critical pavement responses. "UNREIN" in Figure 2 stands for pavement without geogrid and "REIN" means geogrid reinforced pavement. The vertical deflections of geogrid reinforced pavement are less than those observed in unreinforced pavement. This result shows how the vertical deflection distributions predicted along the centreline of loads respond to the applied load. The vertical deflection reduces when pavement is reinforced with geogrid. Based on the result shown in Figure 2, the reduction tends to be maximized at the surface. The difference in vertical deflection between unreinforced and reinforced pavement tends to decrease as the depth increases.

It is known that one of the major factors contributing to subgrade rutting is the magnitude of vertical strain in subgrade. As mentioned earlier, in this study, geogrid reinforcement was placed at the interface between the aggregate base course and subgrade. Once reinforced, pavement is expected to better perform as a result of the placement of geogrid. This can be measured by the magnitude of subgrade vertical strain with and without geogrid reinforcement.

Figure 3 shows the predicted subgrade vertical strains measured at the top of subgrade for unreinforced and reinforced pavement. Apparently, the unreinforced sections exhibit larger subgrade vertical strains than the reinforced ones do. Also observed is the difference between the two becomes greater when the thickness of pavement is thinner and subgrade is weaker. This tells the placement of geogrid improves the strength of subgrade and reduces vertical strains in subgrade. The magnitude of subgrade vertical strains varies in accordance with the configuration of pavement.

In order to further discuss the degree of improvement, percent difference in the magnitude of subgrade vertical strains was compared to one another. As shown in Figure 4, the subgrade vertical strain in geogrid reinforced pavement with weak subgrade is $14-18 \%$ less than that in unreinforced pavement. On the other hand, the subgrade

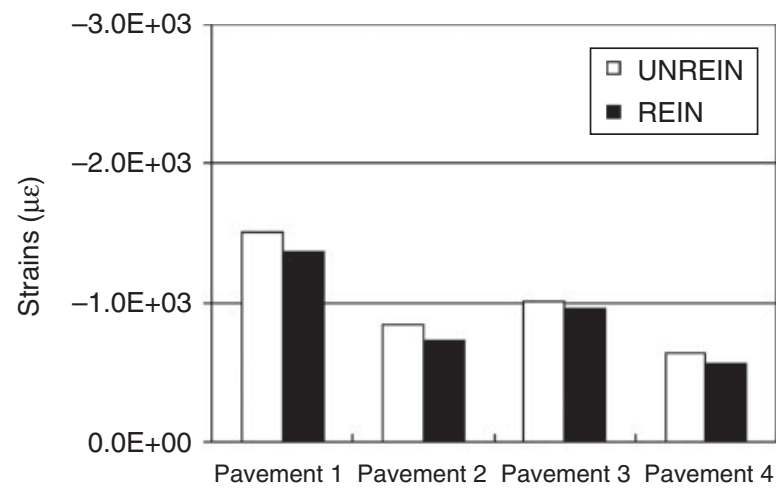

(a) Pavements with strong subgrade

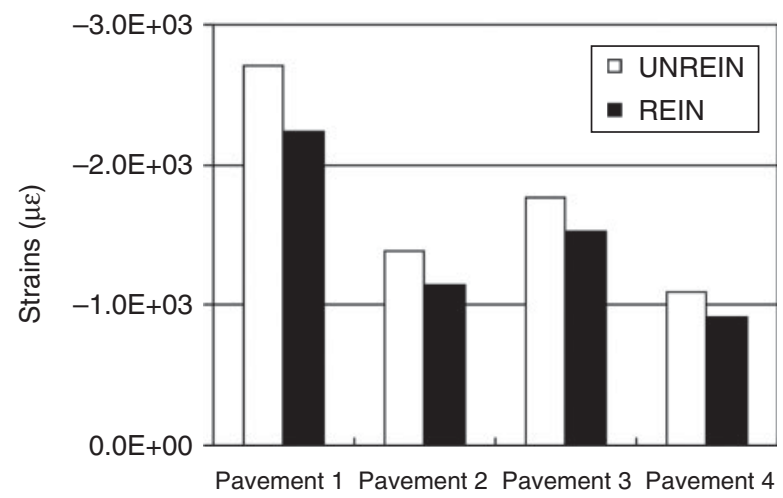

(b) Pavements with weak subgrade

Fig. 3. Predicted vertical subgrade strains from unreinforced and geogrid reinforced pavements: (a) Pavements with strong subgrade; (b) Pavements with weak subgrade

vertical strain in pavement with strong subgrade represents only $5-13 \%$. Overall, the result tells that pavement with weak subgrade takes greater advantage of geogrid reinforcement in flexible pavement. The deformed geogrid reduces the vertical response distribution due to the tensioned membrane effect at the top of subgrade. The result also shows more influence on subgrade responses as

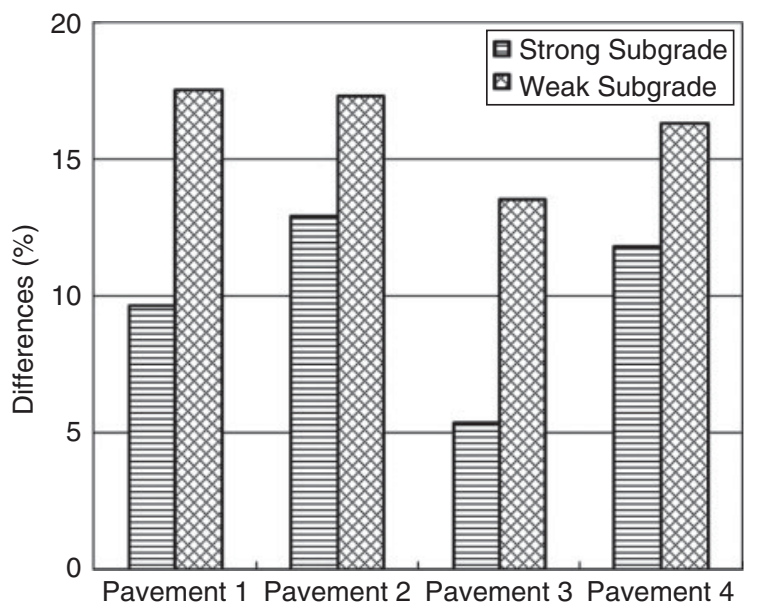

Fig. 4. Differences of subgrade vertical strains in unreinforced and geogrid reinforced pavement 


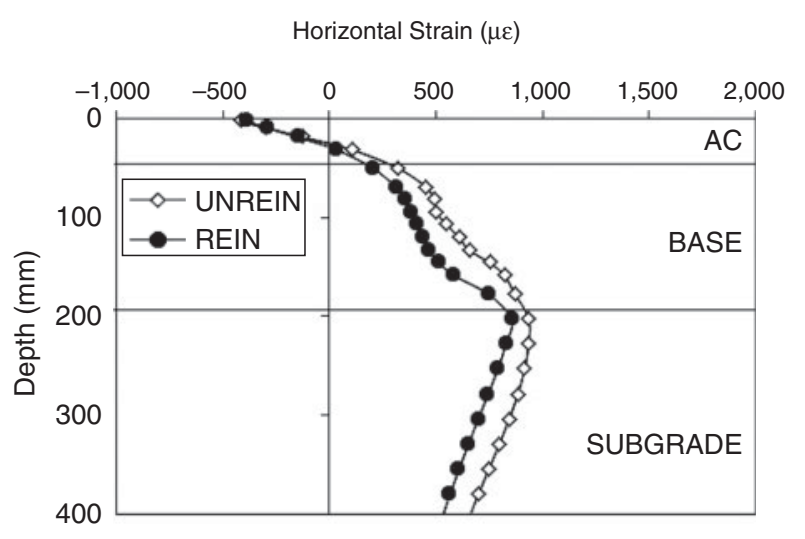

(a) Pavement 1 with weak subgrade

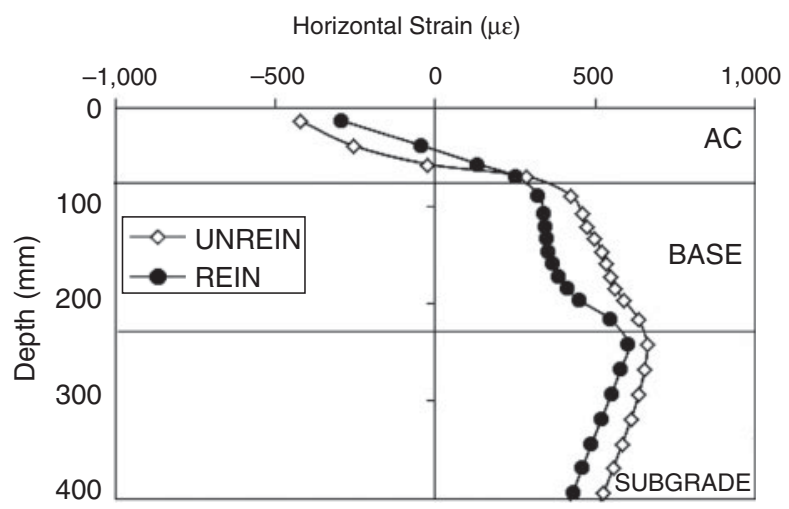

(b) Pavement 3 with weak subgrade

Fig. 5. Predicted horizontal strains in different pavement sections: (a) Pavement 1 with weak subgrade; (b) Pavement 3 with weak subgrade

the thickness of asphalt concrete is thinner. However, with geogrid reinforcement, the thickness of base layer appears relatively less influential to subgrade responses. In summary, regardless of the thickness of the base layer, geogrid reinforcement in thin asphalt concrete layer leads to a significant reduction in vertical subgrade strains when subgrade is weak asphalt.

Another indicator of benefits from the installation of geogrid is confinement of base aggregates by lateral restraint. This can be measured by the increased modulus properties of geogrid reinforced pavement. Figure 5 shows the horizontal stress distributions at the centreline of loads predicted from the two different pavement sections. This shows that the confinement of base aggregates due to constrained lateral motion and developed restraint stress near geogrid influences the horizontal strain distribution.

As shown in Figure 5, the residual stress due to lateral restraint of base aggregates results in less horizontal strains in pavement. The result clearly shows that geogrid reinforces pavement by confining base aggregates and restraining lateral spreading. Also, the placement of geogrid at the interface between base and subgrade led to a significant impact on the tensile strain at the bottom of asphalt concrete layer. This is attributed to the residual stress in the base layer, which is known to be in effect within approximately $10 \mathrm{~cm}$ from the location of geogrid.

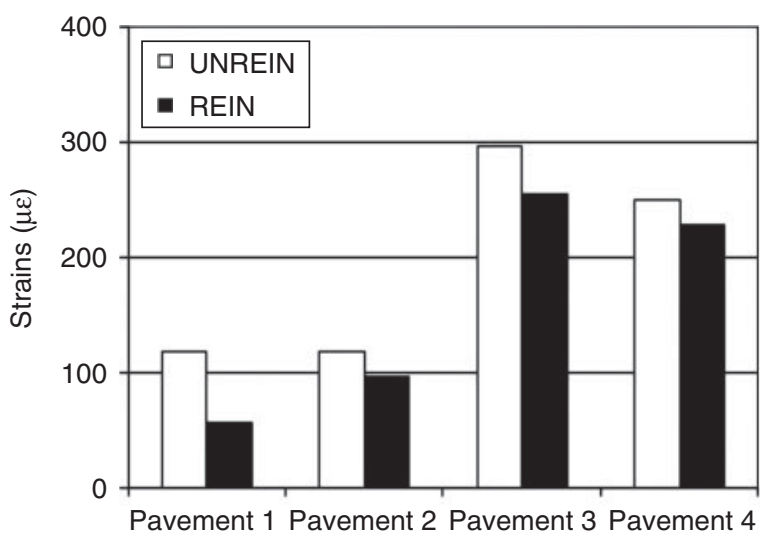

(a) Pavements with strong subgrade

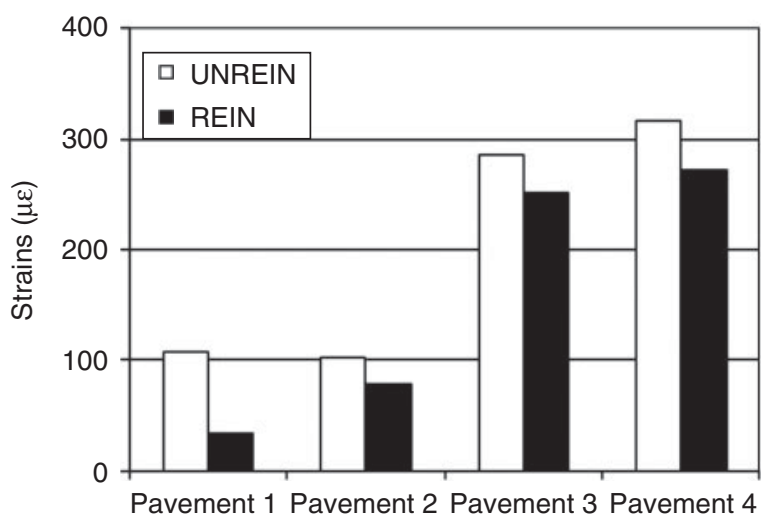

(b) Pavements with weak subgrade

Fig. 6. Predicted tensile strains at the bottom of asphalt concrete layer: (a) Pavements with strong subgrade; (b) Pavements with weak subgrade

The residual stress in the base layer influences the stress and strain distribution in the adjacent pavement layers.

Figure 6 shows the tensile strains at the bottom of asphalt concrete of unreinforced and reinforced pavement. The predicted tensile stresses in geogrid reinforced pavement are less than those in unreinforced pavement. This proves the residual stress as a result of interaction between geogrid and the aggregate layer decreases tensile strains at the bottom of asphalt concrete layer.

Figure 7 shows the differences of tensile strains at the bottom of asphalt concrete in each pavement section. The reduced tensile stresses in geogrid reinforced pavement were observed up to $68 \%$ on weak subgrade and $53 \%$ on strong subgrade. As mentioned above, the residual stress apparently decreases tensile strains at the bottom of asphalt concrete, which in turn benefits the pavement structure. Shown in Figure 7, as the thickness of asphalt concrete becomes thinner, the reduction of tensile strains measured at the bottom of the asphalt concrete layer becomes more evident.

Figure 8 shows the contours of tensile strains for Pavement 3 section on weak subgrade when it is unreinforced and reinforced with geogrid. As the contours of tensile strains exhibit, geogrid is found effective reducing tensile strains in the pavement layers. The 


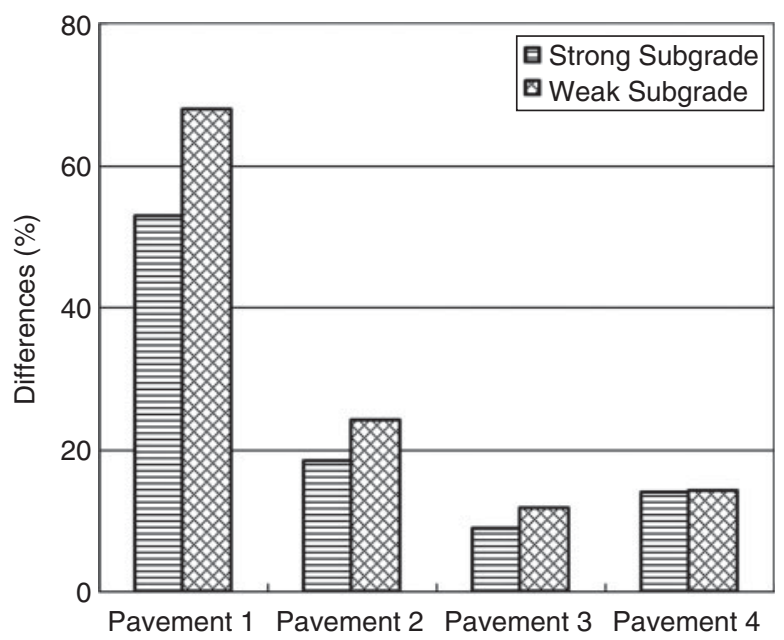

Fig. 7. Differences of tensile strains in unreinforced and geogrid reinforced pavement



(a) Pavement 3 without geogrid on weak subgrade

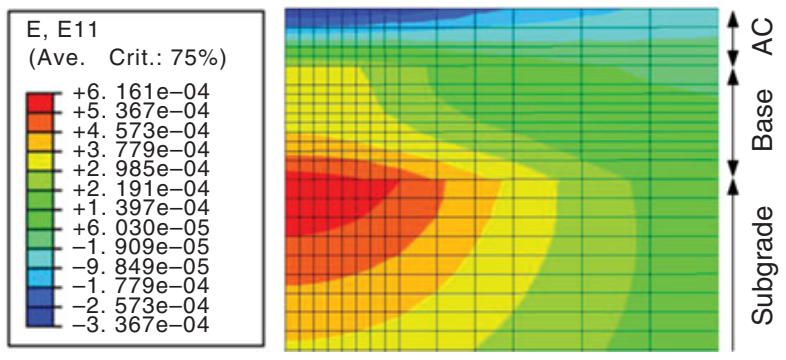

(b) Pavement 3 with geogrid on weak subgrade

Fig. 8. Contours of tensile strains under the center of loading: (a) Pavement 3 without geogrid on weak subgrade; (b) Pavement 3 with geogrid on weak subgrade from the caption

geogrid reinforced section in Figure 8 (b) clearly shows less tensile strains in the base layer and subgrade than the unreinforced section in Figure 8 (a). This tells the placement of geogrid between the base layer and subgrade leads to decrease in tensile strains. As noticed, the residual stress due to the confinement of the aggregate base layer is shown in the entire depth of the base layer and results in better structural performance.

\section{Conclusions}

This paper presents the findings of a study through a 3D $\mathrm{FE}$ analysis of geogrid reinforced flexible pavement in low volume roads. First of all, a 3D FE model was developed to mechanistically solve for the pavement responses under wheel loading and investigate the structural benefits expected in geogrid reinforced low volume flexible pavement. The developed mechanistic model employs nonlinearity of materials in pavement considering the resilient characteristics in base and subgrade under the wheel loading. To properly characterize the resilient response of geomaterials, stress-dependent modulus models were programmed in a user defined material model subroutine in ABAQUS. The interface between aggregate, geogrid, and subgrade was modelled using a contact interface element that shows normal and shear forces between layers. The model also incorporated geogrid reinforcement characteristics and residual stress as a result of aggregate and geogrid interaction.

Four different configurations of pavement were analyzed in this study to measure the differences in pavement responses before and after the installation of geogrid. The results of the analysis indicated that geogrid reinforcement improved the stress distribution within the pavement layer and, therefore, reduced critical pavement responses. The results of the FE analysis were described in terms of surface deflections, subgrade vertical strains, the effect of subgrade properties, and the effect of residual stress. The findings of this study are as follows:

- Surface deflections in the geogrid reinforced pavement sections are smaller than those in the unreinforced pavement sections;

- The reduction in surface deflection appears greater when the asphalt concrete layer is thinner;

- Predicted vertical strains at the top of the subgrade are significantly affected by geogrid reinforcement;

- The placement of geogrid reinforcement reduces vertical subgrade responses;

- The placement of geogrid reinforcement on top of weak subgrade is found particularly effective compared to that on strong subgrade;

- The residual stress resulted from the placement of geogrid significantly influences the reduction of tensile strains at the bottom of asphalt concrete.

According to the 3D FE modelling analysis, surface deflections in the geogrid reinforced pavement sections are smaller than those in the unreinforced pavement sections. It is also found that the reduction in surface deflection appears greater when the asphalt concrete layer is thinner.

The study found that predicted vertical strains at the top of the subgrade layer are significantly affected by geogrid reinforcement. The results of the analysis exhibited the stiffening effect around the geogrid layer due to the increased modulus resulted from the increased confinement at the vicinity of geogrid reinforcement. Such stiffening in aggregate base is believed to reduce vertical strains at the top of subgrade.

The study showed that the placement of geogrid reinforcement tends to reduce vertical subgrade responses in consequence of the tensioned membrane effect. The study also revealed that the placement of geogrid reinforcement on top of weak subgrade is found particularly effective compared to that on strong subgrade. According 
to the results of the analysis, the geogrid reinforced pavement section with weak subgrade displayed larger reduction of vertical strain in subgrade than that with strong subgrade. Compared with unreinforced pavement, up to $18 \%$ reduction of subgrade vertical strain was observed in geogrid reinforced pavement.

The effect of residual stress as a result of confinement between the aggregate base layer and geogrid was investigated measuring tensile stresses at the bottom of asphalt concrete. The results indicated that the residual stress significantly influence the reduction of tensile strains at the bottom of asphalt concrete, which is known to be related to fatigue life of pavement structure. In this study, it was observed up to $68 \%$ of reduction at the bottom of asphalt concrete.

\section{References}

Haas, R. 1984. Structural behavior of Tensar reinforced pavements and some field applications, in Proceedings of Symposium on Polymer Grid Reinforcement in Civil Engineering, Thomas Telford Publishing, London, 166-170.

Haas, R.; Walls, J.; Carroll, R. G. 1988. Geogrid reinforcement of granular bases in flexible pavements, Transportation Research Record 1188: 19-27.

Hibbit, Karlsson and Sorensen (HKS), Inc. 2005. ABAQUS/ standard user's manual, version 6.5, Hibbit, Karlsson \& Sorensen, Inc., Pawtucket, R.I.

Kim, M.; Lee, J. H. 2011. Study on nonlinear pavement responses of low volume roadways subjected to multiple wheel loads, Journal of Civil Engineering and Management 17(1): 45-54. http://dx.doi.org/10.3846/13923730.2011.554012

Kim, M.; Tutumluer, E.; Kwon, J. 2009. Nonlinear pavement foundation modeling for three-dimensional finite element analysis of flexible pavements, International Journal of Geomechanics ASCE 9(5): 195-208. http://dx.doi.org/10.1061/(ASCE)1532-3641(2009)9:5(195)

Konietzky, H.; te Kamp, L.; Gröger, T.; Jenner, C. 2004. Use of DEM to model the interlocking effect of geogrids under static and cyclic loading, in Konietzky, H. (Ed.). Numerical modeling in micromechanics via particle methods. Rotterdam: A. A. Balkema, 3-12.

Kwon, J.; Tutumluer, E.; Kim, M. 2005. Development of a mechanistic model for geosynthetic-reinforced flexible pavements, Geosynthetics International 12(6): 310-320. http://dx.doi.org/10.1680/gein.2005.12.6.310

Kwon, J.; Tutumluer, E.; Konietzky, H. 2008. Aggregate base residual stresses affecting geogrid reinforced flexible pavement response, International Journal of Pavement Engineering 9(4): 275-285.

http://dx.doi.org/10.1080/10298430701582347

Leng, J.; Gabr, M. A. 2002. Characteristics of geogrid-reinforced aggregate under cyclic load, Transportation Research Record 1786: 29-35. http://dx.doi.org/10.3141/1786-04

McDowell, G. R.; Harireche, O.; Konietzky, H.; Brown, S. F.; Thom, N. H. 2006. Discrete element modelling of geogridreinforced aggregates, in Proceedings of the Institution of Civil Engineers, Geotechnical Engineering 159: 35-48. http://dx.doi.org/10.1680/geng.2006.159.1.35

National Cooperative Highway Research Program. 2004. Guide for mechanistic-empirical design of new and rehabilitated pavement structures (Final report), Washington, D.C.: TRB, National Research Council.

Perkins, S. W. 2001. Numerical modeling of geosynthetic reinforced flexible pavements: final report. Montana Department of Transportation, Helena, Montana, Report No. FHWA/MT-01/002/99160-2.

Perkins, S. W.; Edens, M. Q. 2002. Finite element and distress models for geosynthetic-reinforced pavements, International Journal of Pavement Engineering 3(4): 239-250. http://dx.doi.org/10.1080/1029843021000083504

Perkins, S. W.; Ismeik, M. 1997. A synthesis and evaluation of geosynthetic-reinforced base layers in flexible pavements: Part I, Geosynthetics International 4(6): 549-604.

Saad, B.; Mitri, H.; Poorooshasb, H. 2005. Three-dimensional dynamic analysis of flexible conventional pavement foundation, Journal of Transportation Engineering ASCE 131(6): 460-469.

http://dx.doi.org/10.1061/(ASCE)0733-947X(2005)131:6 (460)

Saad, B.; Mitri, H.; Poorooshasb, H. 2006. 3D FE analysis of flexible pavement with geosynthetic reinforcement, Journal of Transportation Engineering ASCE 132(5): 402415. http://dx.doi.org/10.1061/(ASCE)0733-947X(2006)132:5 (402)

Schwartz, C. W. 2002. Effect of stress-dependent base layer on the superposition of flexible pavement solutions, International Journal of Geomechanics ASCE 2(3): 331-352. http://dx.doi.org/10.1061/(ASCE)1532-3641(2002)2:3(331)

Thompson, M. R.; Robnett, Q. L. 1979. Resilient properties of subgrade soils, Transportation Engineering Journal ASCE 105(1): 71-89.

Witczak, M. W.; Uzan, J. 1988. The universal airport pavement design system rep. I granular material characterization. College Park, MD: Department of Civil Engineering, University of Maryland.

Minkwan KIM. PhD, Professional Engineer (PE), Design engineer in Shell International Exploration and Production, USA. He is a member of American Society of Civil Engineers (ASCE) and Transportation Research Board (TRB). His research interests include the computational mechanics of pavement structures focusing on the behavior of pavement including nonlinear material properties and multiple wheels.

Joo Hyoung LEE. PhD, Professional Engineer (PE), Associate Professor in the Department of Construction Science and Organizational Leadership at Purdue University Calumet, USA. He is a member of American Society of Civil Engineers (ASCE). His research interests include pavement design and construction, pavement distress management, and engineeringbased infrastructure management. 